УДК 004.5+007

\title{
ИНФОРМАЦИОННО-КОММУНИКАТИВНЫЕ ТЕХНОЛОГИИ КАК СРЕДСТВО СТРАТЕГИИ ОБЕСПЕЧЕНИЯ ИННОВАЦИОННОЙ БЕЗОПАСНОСТИ И ДОСТИЖЕНИЯ НАЦИОНАЛЬНЫХ ИНТЕРЕСОВ
}

\author{
Г.М. БРОВКА, \\ канд. пед. наук, доцент, декан факультета технологий управления \\ и гуманитаризации \\ Белорусского национального технического университета, г. Минск
}

\begin{abstract}
Аннотация
В последние десятилетия происходит активное внедрение инноваџионных и информационных процессов во все сферы жизни общества и государства (военную, политическую, экономическую, научно-образовательную, социальную, культурную, др.), что способствует ускорению их развития, но одновременно ведет к появлению неизвестных ранее вызовов, рисков и угроз, и требует новых мер обеспечения международной, региональной, наџиональной безопасности.

Ключевые слова: информационно-коммуникативные технологии, инновационная безопасность, национальные интересы, национальная безопасность.
\end{abstract}

Abstract

Last years there is an active introduction of innovative and information processes in all spheres of life of a society and the state (military, political, economic, scientificallyeducational, social, cultural, other) that promotes acceleration of their development, but simultaneously conducts to occurrence of unknown before calls, risks and threats, and demands new measures of maintenance of the international, regional, national safety.

Key words: information and communication technology, innovative security, national interests, national security.

\section{ВВЕДЕНИЕ}

Информационно-коммуникативные технологии (ИКТ) - это совокупность методов, производственных и программно-технологических средств, объединенных в технологическую цепочку, обеспечивающую сбор, хранение, обработку, вывод и распространение информации $[1,3,4,6]$. Информационные технологии предназначены для снижения трудоемкости процессов использования информационных ресурсов. Телекоммуникации составная часть информационных технологий, средства дистанционной передача данных через компьютерные сети и современные технические средства связи.

Результаты деятельности все большего числа работников зависят от информированности и способности эффективно использовать имеющуюся информацию. Все возрастающие потоки информации, которые не всегда доступны широкому кругу пользователей и, в то же время, все возрастающие потребности в использовании информации приводят к так называемому информационному кризису в обществе, создающему риски инновационному развитию $[11,12]$. Преодоление этих кризисов, обеспечение по сути инновационной безопасности в государствах, ставших на путь прогрессивного изменения своего экономико-технологического пространства, осуществляется с помощью нового эволюционного процесса информатизации общества.

Информатизация общества - организованный социально-экономический и научно-технический процесс создания оптимальных условий для удовлетворения информа- 
ционных потребностей и реализации прав отдельных граждан и различных организаций на формирование и использование информационных ресурсов $[1,7]$.

Информационные ресурсы - это совокупность данных, организованных для эффективного получения достоверной информации. Сюда относятся отдельные документы и массивы документов, а также документы и массивы документов в информационных системах (библиотеках, архивах, фондах, банках данных и т.д.) [8].

Бурное развитие компьютерной техники и информационных технологий послужили толчком к развитию общества, называемого постиндустриальным, или информационным. Становление информационного общества происходит на наших глазах. Одновременно стали появляться уже новые риски и угрозы безопасности, возникающие в результате происходящих информатизационных и инновационных процессов $[13,14]$.

От расширенного внедрения информационных технологий в жизнь человека все страны мира перешли к этапу построения информационного общества. Информационное общество отличается от общества, в котором доминируют традиционная промышленность и сфера услуг, поскольку информация, знания, информационные услуги, и все отрасли, связанные с их производством (телекоммуникационная, компьютерная, телевизионная) растут более быстрыми темпами, становятся доминирующими в экономическом развитии, и способствуют образованию новых рабочих мест, вместе с тем происходит сокращение рабочих мест в других «отмирающих» отраслях промышленности, что вызывает социальную нестабильность $[11,12]$.

\section{РЕЗУЛЬТАТЫ И ИХ ОБСУЖДЕНИЕ}

Развитие информационного общества во всех странах признано социально важным процессом, что обусловлено информированностью общества о данном процессе, признанием его как глобального фактора экономического и социального развития, средством повышения социальной мобильности населения.

Информационное общество как объект научного анализа с правовой точки зрения изучается практически во всех странах мира. В научной литературе существует большое количество различных определений понятия «информационное общество», предложенных как зарубежными, так и отечественными учеными. Детальный анализ данных определений не являются нашей задачей. Отметим только классификацию определений, проведенную некоторыми белорусскими учеными. Некоторые авторы (например, Е.М. Ильина) [2] указывают на наличие пяти основных подходов к интерпретации термина «информационное общество»: технократический, гуманитарный, формационный, экономический и политологический. Анищенко В.В. $[1,4]$ выделяет восточный и западный подход к определению информационного общества.

Чаще всего понятие «информационное общество» определяется как особая форма организации общества, в которой создание информации, ее обработка и передача становятся фундаментальными источниками производительности труда. Иными словами, информационное общество - это общество, в котором большинство работающих занято производством, хранением, переработкой и реализацией информации, особенно высшей ее формы - знаний. При этом такими исследователями, как Абламейко С.В., Бровка Н.В. [1], обращается внимание на то, что в информационном обществе процесс компьютеризации позволит гражданам иметь доступ к надежным источникам информации, избавит от рутинной работы, обеспечит высокий уровень автоматизации обработки информации в производственной и социальной сферах. Движущей силой развития общества должно стать производство информационного, а не материального продукта. Материальный же продукт станет более информационно емким, что означает увеличение доли инноваций, дизайна и маркетинга в его стоимости. 
Характерными признаками информационного общества являются:

- формирование единого информационно-коммуникационного пространства в стране как части мирового информационного пространства, равноправное участие всех членов общества в информационной деятельности;

- становление и преобладание в экономике новых компьютерных и информационных технологий, основанных на перспективных телекоммуникациях, средствах вычислительной техники;

- создание и развитие рынка информации, перевод информационных ресурсов общества в ресурсы социально-экономического развития;

- повышение уровня образования на основе внедрения информационных технологий;

- обеспечение прав граждан на свободное получение, использование и распространение информации, как важнейшего условия демократического развития.

В процессе перехода от традиционного общества к информационному возникают новые риски:

- достоверности информации;

- возрастания роли и социальной ответственности средств массовой информации перед обществом за содержание информации;

- соблюдения авторских прав и вторжения информационных технологий в частную жизнь;

- психологической и социальной адаптации общества к информационной среде.

С учетом названных вызовов многие государства принимают меры к институциональному обеспечению национальной безопасности в информационной сфере в целях обеспечения национальных интересов. Можно отметить следующее хронологическое появление законов об информатизации: Закон Республики Узбекистан (май 1993 г.), Закон Украины (июль 1994 г.), Закон Российской Федерации (январь 1995 г.), Закон Республики Беларусь (сентябрь 1995 г.). В странах Европейского союза аналогичные законы появились в конце 1980 - начале 1990-х годов.

Следующим этапом стало принятие национальных стратегических планов, или программ, построения информационного общества (или электронного государства). Так, в США в 1993 году был принят национальный план развития глобальной информационной инфраструктуры, в Канаде стала развиваться «Информационная магистраль». В 1994 году Европейское сообщество поставило в числе стратегических приоритетных задач создание в странах Европы информационного общества, для чего был создан проект «Электронная Европа». Периодически этот проект анализируется и уточняется, в последнее время он трансформирован в проект «I2010 - A European Information Society for growth and employment».

В 2000 году была принята Окинавская хартия глобального информационного общества. На всемирных встречах на высшем уровне в Женеве (декабрь 2003 г.) и Тунисе (ноябрь 2005 года) разработаны Декларация принципов и План действий. Генеральная Ассамблея ООН одобрила Тунисское обязательство и Тунисскую программу для информационного общества.

В настоящее время национальные стратегии развития Информационного общества и построения электронного правительства приняты более чем в 90 странах.

В опубликованном 21.02.2011 года докладе ЕС по внедрению электронного правительства отмечается, что все больше людей во всех странах ЕС в настоящее время имеют доступ к государственным услугам через Интернет. Среднее число оказываемых государственных услуг через Интернет в ЕС выросло с 69 \% до 82 \% с 2009 по 2010 год. Хотя имеется достаточно большое неравенство между странами. Европейский Союз ставит цель, чтобы к 2015 году половина всех граждан при решении вопросов по четырем из пяти видов бизнеса использовала средства Интернета и электронного правительства. 
Рубеж тысячелетий совпал с переходом человечества к пятой — технологической революции и стадии развития, которую обозначают обычно как общество знания и «информационно-коммуникационное общество» [11]. Большинство специалистов сходятся в том, что можно выделить взаимосвязанные характерные его черты:

- лавинообразное нарастание информационной насыщенности хозяйственной, управленческой и других сфер деятельности и превращении информации в фактор социально-экономического развития;

- становление рыночной инфраструктуры потребления информации и информационных услуг;

- постепенное замещение централизованных структур сетевыми типами организации, приспособленными к быстрым, гибким изменениям и развитию.

На этой основе создаются предпосылки для значительного повышения эффективности производства, для экономии природных ресурсов и защиты окружающей среды, для перехода к устойчивому развитию.

Осознавая все преимущества информационного общества, нельзя не учитывать, что оно несет с собой не только новые решения и возможности, но и новые вызовы, риски и угрозы. Последствия их применения целиком зависят от ценностных установок и политических решений и требуют разработки стратегии обеспечения национальной безопасности в сфере инноваций и в том числе использования информационных технологий. Что позволит проводить адекватную политику и принимать своевременные управленческие решения на всех уровнях государственного управления [13, 14].

Важнейшей особенностью информационного общества и его рисками является перенос акцента в производстве с обработки материалов на производство информации и оказание услуг. Преимущественное развитие «третичного» сектора экономики оказания услуг - приводит к существенному изменению удельного веса этих отраслей в формировании валового национального продукта. В целом ряде европейских стран более половины оборота средств в информационной индустрии приходится на создание информационных продуктов и технологий и лишь $45 \%$ - на производство техники; в индустрии связи разрыв еще более радикальный: $80 \%$ составляют телекоммуникационные услуги и только $20 \%$ - производство средств коммуникации.

Очевидна тенденция увеличения доли людей, занимающихся обработкой информации, в общей структуре занятости развитых стран. С точки зрения американского экономиста Т. Стюарта[1], и председателя совета директоров компании Google Э. Шмидта [12], информационный век наступил в 1991 году, когда впервые американские компании больше затратили на приобретение информационной техники, необходимой для манипулирования с информацией (компьютеры и телекоммуникационное оборудование), чем на промышленное оборудование, предназначенное для разного рода действий с материальными предметами (двигатели, турбины, станки и механизмы, машины и т.п.). По некоторым расчетам, доля американцев, чей труд в основном связан с физическим трудом в сфере производства или услуг (сельхозрабочие, ремесленники, механики, розничные торговцы, парикмахеры и т.п.), сократился с 83 \% в 1900 году до $41 \%$ в начале XXI века $[1,5]$. Аналогичные изменения происходят и в других странах. Именно поэтому одно из самых распространенных определений информационного общества такое: информационным называется общество, в котором обработкой информации занято больше людей, чем обработкой сырья и материалов.

Перестройка мировой экономики, начавшаяся в середине 1970-х годов, привела к смене доминирующей формы организационной структуры предприятия и межфирменного сотрудничества. Целью организационных изменений была адаптация к резко возросшим темпам изменений в финансовой, экономической, институциональной и технологической среде деятельности фирм. Общее направление изменений - переход от вертикальных иерархических структур к гибким сетевым формам организации, причем 
сети стали формообразующей основой как внутренней организации современной корпорации, так и ее взаимодействия с партнерами (межфирменные сети, корпоративные стратегические альянсы и т.п.). Аналогичные организационные изменения происходят в сфере услуг, административных органах и других областях деятельности. Развитие информационно - коммуникационных технологий (ИКТ) стимулировало происходящие изменения, позволило выявить все преимущества новой формы экономико-социальной организации, хотя организационные изменения возникли и развивались первоначально независимо от технологического развития. Со своей стороны, развитие телекоммуникационной инфраструктуры, и прежде всего Интернета, привело к тому, что все больше транзакций в современной экономике и обществе совершаются с использованием компьютерных сетей. Интернет становится глобальной средой общения, труда и отдыха. В первоначальный период сложно было предвидеть риски и угрозы, возникающие для этих синергетических инновационных процессов, и тем более рисков и угроз всем сферам национальной безопасности в результате внедрения инновационных технологий, в особенности информационно-коммуникационных.

Информационно-коммуникационные технологии стали подлинной движущей силой мирового экономического и технологического развития, преумножая сегодняшние знания и духовные ценности, расширяя сферы использования достижений науки и техники. Стало очевидным преобладание информационной составляющей деятельности людей над всеми другими ее формами и компонентами. Стремительно растет удельный вес отраслей, относящихся к созданию, использованию и передаче информации. Сегодня этот показатель в наиболее передовых странах приближается к 25 \% национального валового продукта. И при этом с каждым днем необходимо затрачивать все большие средства (и финансовые, и материальные, и трудовые ресурсы) для обеспечения безопасности функционирования ИТК систем во всем мире, и тем более - в передовых государствах.

По мере того как информация становится самым ходовым товаром в мире, ведущие корпорации становятся богаче, чем многие страны средних размеров. Глобализация заставляет предпринимателей вступать в жесткую конкуренцию, в результате которой выживают действительно сильнейшие, которые затем получают большую реальную власть, начинают оттирать с рынка новых игроков и вовсе не подпускать к нему слабых.

Такой «передел» мира может отразиться не только на судьбе субъектов предпринимательства, но и на развитии цивилизации. Главная опасность заключается в том, что усиливающаяся глобализация производства и мобильность всемирных корпораций может неблагоприятным образом повлиять на обеспечение национальной безопасности государств, а также политику охраны окружающей среды, право на труд и социальную защиту человека. Развитие и широкое использование ИКТ привело к появлению еще одного измерения бедности, - так называемой «информационной бедности» [12]. Это понятие отражает рост социальной дифференциации населения по новому принципу принципу возможностей доступа к современным ИКТ, когда лишь часть населения получает доступ к новым технологиям и информационным ресурсам и может реализовать это преимущество. «Бедным» остается рассчитывать на то, что благодаря ускорению процесса технологической инновации, вовлечению индустриального капитала и конкуренции новая сетевая технология и инфраструктура постепенно будут становиться все дешевле, а потому доступнее для большего числа людей. Широкое внедрение ИКТ во все сферы жизни ведет к появлению не только таких новых форм социальной и экономической деятельности как электронная коммерция, но и таких, как телеработа, дистанционное образование, телемедицина и электронное правительство. Не следует забывать, что этот ресурс ведет и к соблазну использовать его для экспорта цветных революций, дестабилизации общества, внедрению псевдодемократических виртуальных ценностей. 
Сегодня четко обозначилась тесная связь между образованием, обучением и развитием, поэтому ключевым фактором для любой отрасли, организации или компании становится эффективный доступ к образованию и непрерывное обучение. Во многих странах реальностью становится развертывание массовой системы качественного обучения на расстоянии, и образования, не ограниченного возрастными рамками, системы постоянного повышения квалификации. Улучшение подготовки специалистов открывает компаниям и учреждениям новые горизонты в управлении персоналом, а значит и возможности роста производства. В свою очередь, для каждого работника это означает более успешную и динамичную карьеру, большую мотивацию к труду. Система образования, в свою очередь, должна будет приучать ребенка, подростка и взрослого к необходимости постоянных изменений в образе жизни, к восприятию нового. То есть государство может успешнее решать задачу накопления человеческого капитала.

В информационном обществе обычным явлением станет «телеработа», которая в состоянии кардинально решить проблему занятости, в том числе для людей с ограниченными физическими возможностями, что может помочь решению одной из самых сложных социальных проблем. Кроме того, с массовым распространением телеработы связываются надежды на решение такой острой проблемы больших городов, как перегрузка транспортной системы и загрязнение воздуха выхлопными газами.

В условиях бурного развития новых информационно-коммуникационных технологий, безусловно, произойдут существенные перемены в традиционных СМИ - в печати, радио, телевидении, в доступе к ним, в способах доставки и, вероятно, в содержании. Радио- и телевизионные передачи, как правило, размещаются в интернете в двух формах аудиовизуальной и текстовой. Текст становится общим знаменателем для всех СМИ в интернете. При этом газета или журнал имеют большие преимущества, поскольку публикуемая там информация, как правило, отработана высококвалифицированными специалистами, в результате чего читатель получает тщательно проанализированные, хорошо обработанные сведения. Сейчас газетам и журналам проще перейти к электронной версии, чем телеканалам, но со временем, возможно, ситуация изменится.

С появлением глобальной сети возникли и принципиально новые СМИ - электронные газеты. Электронная газета имеет ряд особенностей. Одна из них состоит в том, что такое издание постоянно обновляется, часто хорошо иллюстрировано и в нем нет, как правило, законченных статей. Материал заканчивается тогда, когда заканчивается событие. В этом смысле журналисты в газете, живущей в интернете, должны работать постоянно и их статьи пишутся таким образом, чтобы последняя фраза всегда могла бы быть дополнена. Электронные газеты уже сейчас опережают не только традиционные печатные СМИ, но и телевидение по скорости распространения информации.

Глобализация, порожденная взрывным развитием ИКТ, созданием планетарных сетей, триумфом рыночной экономики, либерализацией международной торговли, развитием транспорта, приводит к размыванию национальных и политических границ и к ускорению темпов индустриализации и унификации культур. Многие развитые и развивающиеся страны в полной мере осознали те колоссальные преимущества, которые несет с собой развитие и распространение информационно-коммуникационных технологий. Ни у кого не вызывает сомнения тот факт, что движение к информационному обществу - это путь в будущее человеческой цивилизации. Именно это фиксирует Окинавская хартия глобального информационного общества, которая подписана руководителями ряда ведущих стран в августе 2000 г.

Информационное общество стало политической целью развития многих государств и регионов. Уже более 20 лет оно является предметом программных разработок, в том числе и в области стратегий обеспечения международной, региональной и национальной безопасности на национальном, международном и региональном уровнях, основная цель которых - обеспечить максимальную пользу и снизить риски, угрозы и 
негативные последствия. Например, в условиях интенсивного использования глобальных сетей возникают новые формы агрессии со стороны наиболее развитых стран в отношении менее развитых, появляется опасность утраты целыми сообществами своей культурной и национальной самобытности, происходит навязывание человечеству потребительских предпочтений и вкусов в интересах узкой группы транснациональных компаний-производителей. В условиях существования открытых, легкодоступных и легко наполняемых информационных сетей возникает проблема ограничения информации, считающейся социально и экономически опасной, проблема безопасности персональных и других видов данных, проблема соблюдения авторских прав и прав производителей электронной информации $[13,14]$.

В ответ на вызовы информационного века в последние несколько лет практически все развитые и многие развивающиеся страны начали разрабатывать национальные программы формирования информационного общества, стратегии и концепции информационной и научно-технологической безопасности, а некоторые даже приступили к их реализации. Первая такая программа, известная как «Национальная информационная инфраструктура», появилась в начале 90-х годов в США. Осознав свое отставание, Европа в соответствии с Пятой рамочной программой исследований объявила проект «Технологии информационного общества». Однако неудовлетворительные результаты первого года его выполнения побудили Европейскую Комиссию в конце 1999-го выступить с новой инициативой - «Электронная Европа», которая была призвана активизировать деятельность по формированию общеевропейского информационного общества. Наряду с общеевропейской инициативой есть национальные программы у Великобритании, Франции и многих других стран Европы и мира. В развитых странах уже приняты документы третьего поколения, подводящие промежуточные итоги и ставящие новые цели в построении информационного общества. Европейский Союз, который имеет специальный комиссариат по вопросам информационного общества, разработал концепцию новой экономической революции, в которой утверждается, что Европа может развиваться только в условиях нового электронного экономического пространства.

Мировой опыт показывает, что каждая страна движется к информационному обществу своим путем от начального рубежа, определяемым сложившимися политическими, социально-экономическими и культурными условиями [11]. Политические и социально-экономические условия, в которых еще 10-15 лет будет происходить переход стран СНГ к информационному обществу, существенно отличаются от условий, характерных для развитых стран. В последних имеется эффективно функционирующая рыночная экономика, обеспечивающая постоянный рост информационных потребностей и платежеспособный спрос на информационные продукты и услуги, есть мощный средний класс, являющийся основным потребителем информационных услуг. Экономики этих стран располагают свободными средствами для инвестирования в развитие информационно-коммуникационной инфраструктуры.

В большинстве развитых стран имеется хорошо развитая база производства и предоставления населению информационных продуктов и услуг, сложилась система компьютерного образования и стремительно расширяется сфера услуг, предоставляемых сетью Интернет. Государства СНГ находятся только в начале пути. Несмотря на большой опыт решения вопросов информатизации, мы задержались в разработке современных программ, учитывающих проблематику информационного общества. Но, ставя перед собой цели решения стратегических задач всемерного развития общества, обеспечения экономической безопасности, содружество не может остаться в стороне от общей тенденции.

Одной из основополагающих характеристик информационного общества является становление и развитие глобальной информационной инфраструктуры [1]. 
В исследовании, проведенном департаментом ООН по экономическим и социальным вопросам и опубликованном 2 марта 2012 г., отражено состояние дел по созданию электронного правительства. В нем отмечается, что Республика Беларусь, например, занимает 61-е место из 193 стран мира. В рейтинге по уровню развития телекоммуникационной инфраструктуры по сравнению с 2008 годом Беларусь поднялась с 84-го на 48-е место.

Законом Республики Беларусь от 10 ноября 2008 года № 455-3 «Об информации, информатизации и защите информации» определено, что государственное регулирование и управление в данной сфере осуществляется Президентом Республики Беларусь, Советом Министров, НАН Беларуси, Оперативно-аналитическим центром при Президенте Республики Беларусь, Министерством связи и информатизации, иными государственными органами в пределах их компетенции. В рамках Государственной программы «Электронная Беларусь» были выполнены проекты, направленные на развитие технологической инфраструктуры оказания государственных информационных услуг на основе использования информационно-коммуникационных технологий.

В 2003-2006 годах созданы автоматизированные информационные системы практически для всех органов государственного управления. С 2007 по 2010 год создавалась информационно-коммуникационная инфраструктура, ориентированная в первую очередь на формирование системы оказания государственных информационных услуг, разрабатывались информационные системы взаимодействия государственных органов и потребителей (граждан и организаций), в том числе на основе реализации принципа «одного окна».

В числе других мероприятий Государственной программы «Электронная Беларусь», направленных на предоставление государственных информационных услуг и имеющих важные практические результаты, отмечаются следующие:

1) создание корпоративной библиотечной сети в составе Национальной библиотеки Беларуси, республиканских и областных библиотек и региональных информационных центров. Сеть обеспечивает доступ к библиотечным информационным ресурсам широкому кругу пользователей, включая жителей сельских районов республики;

2) создание автоматизированных систем, обеспечивающих на основе заявительного принципа «одно окно» электронное взаимодействие государственных органов и организаций при выполнении административных процедур при выдаче справок

3) разработка единой информационно-аналитической среды для сбора, обработки данных, наблюдения, диагностики и обмена медицинской информацией в оперативном режиме;

4) создание общереспубликанской системы и базы данных по сбору налогов от физических лиц - граждан Республики Беларусь;

5) создание автоматизированной системы пограничного контроля на всех пунктах пропуска через Государственную границу Республики Беларусь, что позволило значительно ускорить и упростить процедуру оформления документов гражданами Республики Беларусь при пересечении государственной границы [9].

В рамках Государственной программы «Электронная Беларусь» создана общегосударственная автоматизированная информационная система (ОАИС). В 2009 году внедрена базовая версия программного обеспечения интеграционного ядра и порталов ОАИС, на базе национального оператора электросвязи РУП «Белтелеком» создана техническая инфраструктура для развертывания программно-технического комплекса ОАИС.

Важными факторами становления информационного общества в нашей стране являются:

- Создание сети библиотек Республики Беларусь.

- Создание Парка высоких технологий, который вносит важный вклад в процесс становления информационного общества. Парк высоких технологий создан с целью 
разработки в Республике Беларусь программного обеспечения, информационнокоммуникационных и других технологий, направленных на повышение конкурентоспособности национальной экономики, создание уникальной благоприятной среды для развития высоких технологий. Гарантией успешного функционирования Парка является создание для деятельности резидентов благоприятных экономических, социальных и правовых условий.

- Повышение качества образования и рынка в области IT-технологий. По оценкам экспертов, на белорусском рынке экспортно-ориентированного программирования работают квалифицированные специалисты с высоким уровнем образования. В последние годы белорусские инженеры, ученые, программисты участвуют в широкомасштабных технологических проектах (создание космических станций, мощных компьютерных и глобальных коммуникационных систем, ядерные разработки и др.). Увеличивается количество белорусских специалистов, занятых на рынке экспортного программирования. Так, белорусские компании EPAM, IBA, Sam-Solutions, Belsoft, ScienceSoft выполняют проекты для British Telecom, T-Mobile, Cingular/ATT, BlueCross BlueShield, Reuters, Лондонской Фондовой Биржи, AeroMexico, William Hill, SAP, Microsoft, Hyperion, BEA, Colgate, Samsung, IBM, Siemens, Alcatel и других (по данным Национального инвестиционного сайта Республики Беларусь) [10].

- Развитие национальных компьютерных технологий, средств обработки и хранения мощных потоков информации. В стране действует Республиканский суперкомпьютерный центр коллективного использования, как структурное подразделение Национальной Академии Наук Беларуси. Он объединяет вычислительные мощности суперкомпьютерных конфигураций «СКИФ».

- Все большее использование компьютерных и информационных технологий в быту. Компьютеры используются в жилищах, например, с целью обеспечения их нормальной жизнедеятельности (охранная, противопожарная или газовая автоматика; управление освещенностью, расходом электроэнергии, отопительной системой, бытовыми приборами со встроенными микропроцессорами). Компьютеры также используются для обеспечения информационных потребностей людей (заказы на товары и услуги; обеспечение справочной информацией).

Об активном развитии в Беларуси частного IT-сектора свидетельствует тот факт, что первые частные IT -компании появились в нашей стране в конце 1980-х - начале 1990-х годов. Развитию частного IT-сектора способствовало принятое в 2004 году решение Президента Беларуси о создании Парка высоких технологий. В Парке высоких технологий в 2011 году было зарегистрировано 94 компании-резидента, общая численность работающих на 1 января 2011 г. составила 9421 человек, объем производства компьютерных программ его резидентами в 2010 году составил 590 млрд. рублей и вырос по сравнению с 2009 годом на 47 \%. [10].

\section{ВЫВОДЫ}

Изложенное выше позволяет сделать вывод о значительной роли государства в формировании информационного общества. Следует однозначно констатировать, что ни одно общество не может рассчитывать на успешное внедрение результатов пятой технологической революции без определяющей государственной поддержки и регулирования.

Стратегическими задачами ближайшего будущего для государств СНГ должны стать вопросы правового и организационного характера, препятствующие динамичному развитию общества знания - информационного общества:

- решение проблем защиты и охраны авторских прав и интеллектуальной собственности, в том числе на цифровой контент и программное обеспечение; 
- ускорение создания нормативно-правовой базы для предоставления органами власти электронных государственных услуг;

- совершенствование государственной системы управления процессами информатизации.

- развитие инфраструктуры государственной системы оказания информационных услуг в электронном виде.

То есть создание эффективной системы оказания государственных электронных услуг, включая развитие национальной информационно-коммуникационной инфраструктуры, обеспечивающей опережающее развитие растущих информационных потребностей граждан, бизнеса и государства. Одной из составляющих задач оказания государственных электронных услуг является создание республиканской иерархической системы, охватывающей различные уровни - республиканский, областной, районный и сельский.

Обеспечение информационной и инновационной безопасности государств в долгосрочной перспективе будет зависеть от безусловной реализации Стратегий развития, в т.ч. концептуально прописанных в Государственных программах и имеющегося положительного опыта ряда стран. Так, например, Стратегия развития информационного общества Республики Беларусь на период до 2015 года, утвержденная постановлением Совета Министров Республики Беларусь от 9 августа 2010 г. № 1174, позволяет четче сформулировать цели на период до 2020-2030 годов и выбрать реальные пути их достижения. Важное значение для информатизации республики и ее продвижения на пути построения информационного общества имеет Национальная программа ускоренного развития услуг в области информационных технологий на период 2011-2015 годы, утвержденная постановлением Совета Министров Республики Беларусь от 28 марта 2011 г. № 384.

Основной целью названной выше Национальной программы является создание условий для ускоренного развития услуг в сфере информационно-коммуникационных технологий, содействующих развитию информационного общества на инновационной основе и способствующих повышению качества и эффективности информационных отношений населения, бизнеса и государства, в том числе, формированию государственной системы оказания электронных услуг.

Указанная Национальная программа структурно состоит из девяти подпрограмм и включает 147 мероприятий, из них 106 НИОКР и 41 - организационно-техническое (в том числе четыре инвестиционных). В качестве подпрограмм определены следующие: «Национальная информационно-коммуникационная инфраструктура», «Электронное правительство», «Электронное здравоохранение», «Электронная занятость и социальная защита населения», «Электронное обучение и развитие человеческого капитала», «Формирование национального контента», «Электронная таможня», «Безопасность ИКТ и цифровое доверие», «Развитие экспортно-ориентированной ИТ-индустрии». Перечисленные подпрограммы охватывают важнейшие направления дальнейшего развития информационного общества и соответствуют аналогичным программам многих стран.

\section{ЛИТЕРАТУРА}

1. Абламейко С.В., Новик И.А., Бровка Н. В. Краткий курс истории вычислительной техники и информатики, Минск, БГУ, 2014.

2. Ильина Е. М. На пути к информационному обществу: государство, политика, информация в Республике Беларусь, Минск, 2010.

3. Васильев В.Н., Стафеев С.К. Компьютерные информационные технологии основа образования XXI века,в журнале Комплексные инструменты в образовании, 2002, N1, c. 3-7. 
4. Абламейко С.В., Марушко Д. А. К вопросу о правовом обеспечении информационной безопасности при формировании информационного общества в Республике Беларусь, Известия НАН Беларуси №4, с. 39-45.

5. Норенков И.П. Краткая история вычислительной техники и информационных технологий / Приложение к журналу "Информационные технологии" № 9/2005, Изд-во «Новые технологии», «Информационные технологии», Приложение, 2005.

6. Фринланд, А.Я. Основные ресурсы информатики: учеб.пособие / А.Я. Фринланд. - Тула: Изд-во Тул. гос. пед. ун-та, 2004. - 253 с.

7. Телешкола:: Энциклопедия:: Информатика. - [Электронный ресурс]. - Режим доступа: http://www.internet-school.ru/Enc.ashx?item=3479.

8. Зуев К.А. Компьютер и общесто - М.: Изд-во полит.лит-ры, 1990.

9. Леонтьев В.А. - «Новейшая энциклопедия Интернета 2008» - ОЛМА-ПРЕСС: Образование, 2008.

10. Парк высоких технологий. - [Электронный ресурс]. - Режим доступа: http://invest.belarus.by/ru/investment/htp/

11. Carlota Perez Technological Revolutions and Financial Capital. The Dynamics of Bubbles and Golden Ages / Edward Edgar Cheltenham, UK, Northampton, MA, USA.

12. Эрик Шмидт и Джаред Коэн Новый цифровой мир. Как технологии меняют жизнь людей, модели бизнеса и понятие государства / Издательство «Манн, Иванов и Фербер», Москва, 2013.

13. Бровка Г.М. ЕАЭС: инновационное развитие и возникающие риски / // В сб.: «Общая история единения народов. Роль лидеров Казахстана и Беларуси в становлении и развитии независимых государств»: матер. докл. Междун. научной конф - Минск, БНТУ, 21 марта 2015. - С.38-44.

14. Бровка Г.М. Вызовы и угрозы национальным интересам в контексте инновационного развития / // В сб.: «Влияние внешней политике на национальный интерес»: матер. докл. Междун. научной конф - Кишинев, 15 мая 2015. - C.37-42.

Статья поступила в редакцию 13 ноября 2015 года. 